\title{
Rockfall induced seismic signals: case study in Montserrat, Catalonia
}

\author{
I. Vilajosana ${ }^{1}$, E. Suriñach ${ }^{1}$, A. Abellán ${ }^{1}$, G. Khazaradze ${ }^{1}$, D. Garcia ${ }^{1}$, and J. Llosa ${ }^{1,2}$ \\ ${ }^{1}$ Grup d'Allaus (RISKNAT), Dept. Geodinàmica i Geofísica, Fac. de Geologia, Universitat de Barcelona, \\ C/Martí i Franquès s/n, 08028 Barcelona, Spain \\ ${ }^{2}$ Universitat Oberta de Catalunya, Internet Interdisciplinary Institute Tecnologia, \\ Av. del Canal Olímpic s/n, 08860 Castelldefels (Barcelona), Spain
}

Received: 17 March 2008 - Revised: 21 May 2008 - Accepted: 27 June 2008 - Published: 5 August 2008

\begin{abstract}
After a rockfall event, a usual post event survey includes qualitative volume estimation, trajectory mapping and determination of departing zones. However, quantitative measurements are not usually made. Additional relevant quantitative information could be useful in determining the spatial occurrence of rockfall events and help us in quantifying their size. Seismic measurements could be suitable for detection purposes since they are non invasive methods and are relatively inexpensive. Moreover, seismic techniques could provide important information on rockfall size and location of impacts.

On 14 February 2007 the Avalanche Group of the University of Barcelona obtained the seismic data generated by an artificially triggered rockfall event at the Montserrat massif (near Barcelona, Spain) carried out in order to purge a slope. Two 3 component seismic stations were deployed in the area about $200 \mathrm{~m}$ from the explosion point that triggered the rockfall. Seismic signals and video images were simultaneously obtained. The initial volume of the rockfall was estimated to be $75 \mathrm{~m}^{3}$ by laser scanner data analysis. After the explosion, dozens of boulders ranging from $10^{-4}$ to $5 \mathrm{~m}^{3}$ in volume impacted on the ground at different locations. The blocks fell down onto a terrace, $120 \mathrm{~m}$ below the release zone. The impact generated a small continuous mass movement composed of a mixture of rocks, sand and dust that ran down the slope and impacted on the road $60 \mathrm{~m}$ below. Time, time-frequency evolution and particle motion analysis of the seismic records and seismic energy estimation were performed. The results are as follows: 1 - A rockfall event generates seismic signals with specific characteristics in the time domain; 2 - the seismic signals generated by the mass movement show a timefrequency evolution different from that of other seismogenic
\end{abstract}

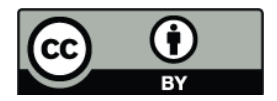

Correspondence to: I. Vilajosana (vilajosana@ub.edu) sources (e.g. earthquakes, explosions or a single rock impact). This feature could be used for detection purposes; 3 - particle motion plot analysis shows that the procedure to locate the rock impact using two stations is feasible; 4 - The feasibility and validity of seismic methods for the detection of rockfall events, their localization and size determination are comfirmed.

\section{Introduction}

Land use planning based on hazard mapping is one of the most cost effective ways of protecting inhabited areas. Zones endangered by rockfall events have increased in the last decades as a result of increased infrastructure and population growth in mountain areas. Defence structures are usually installed to protect the affected areas. However, suitable design and the distribution of the mitigating measures demand an accurate characterization of the rockfall events, including the determination of the energies involved and mapping of the arrival zones. Mapping procedure is usually based on numerical simulation of rockfall trajectories and impact energies. The results obtained from the simulations must be validated through information from rockfall catalogues, population polls or using information extracted from post event observations. However, these observations are usually scarce and not cost effective.

Typical post event surveys include qualitative volume estimation, trajectory mapping and determination of departing zones. However, quantitative measurements are usually not made. Quantitative information could help in determining the spatial occurrence of rockfall events and in quantifying its size and frequency. Seismic measurements might help to provide this information. On one hand, they could be used for detection purposes since they are non invasive and relatively

Published by Copernicus Publications on behalf of the European Geosciences Union. 
cheap. On the other hand, they could yield important information on rockfall occurrence, size and location of impact as a consequence of the characteristics of the rockfall seismic wave field propagation. The snow avalanche team of the Universitat de Barcelona (UB) has been studying the characteristics of snow avalanches using seismic methods since 1994, (Sabot et al., 1998; Suriñach, 2004). We have studied the seismic signals of avalanches in the valleys of Boí Taüll and Núria (Catalan Pyrenees), Valleé de La Sionne (Swiss Alps) and at the test site in Ryggfonn (Norway). In addition, recently the group undertook studies on the seismic characteristics of other mass movements such as landslides and mud flows (Suriñach et al., 2005; Vilajosana et al., 2007). We seek to contribute to a reliable detection of snow avalanches and other mass movements using seismic methods. In this regard, in order to deal with the detection and characterization of rockfall events, we took advantage of the artificially released rockfall triggered in the Montserrat massif (Barcelona) on 14 February 2007 to record the seismic signals generated by the mass movement. Earlier studies especially focused on the analysis of seismic signals produced by rockfall events are scarce, and are mainly concerned with scales that are completely different from the scales presented in this work. A notable example was presented in Norris (1994) where 14 seismic signals generated by avalanches and rockfall events were analyzed. In this study, rockfall volumes ranged between $10^{4} \mathrm{~m}^{3}$ and $10^{7} \mathrm{~m}^{3}$. The seismic signals produced were recorded by seismic stations located at about $70 \mathrm{~km}$ from the source. Recently, Deparis (2007) presented a study on the seismic signals generated by large rockfall events $\left(10^{3}-10^{6} \mathrm{~m}^{3}\right)$ in the French Alps. These signals were recorded by the regional seismic network (SISMALP) at distances between 25 and $250 \mathrm{~km}$. Deparis (2007) showed that although the localization of the events is possible, the large distances and the small number of available sensors restricted the detection capabilities of the seismic array to only large events $\left(>10^{3} \mathrm{~m}^{3}\right)$.

In the present work our interest is centred on a completely different scale of the phenomenon. We are interested in rockfall events with volumes ranging between $1 \mathrm{~m}^{3}$ and $10^{3} \mathrm{~m}^{3}$. Such events are more frequent than large events. They usually affect protective infrastructures and buildings or roads. The study presented here is focused on the validation of the methodologies of seismic signal analysis to detect and characterize this type of rockfall event. The data obtained in a controlled experiment are helpful in achieving our goal.

\section{Experiment description}

The Montserrat massif is located $40 \mathrm{~km}$ North West of Barcelona (Fig. 1). After a natural rockfall event of about $30 \mathrm{~m}^{3}$ at "El Cami dels degollats", which blocked the main road, the local authorities decided to purge the slope using explosives. On 14 February 2007 the artificial release of an unstable boulder was carried out. Two seismic stations composed of a Lennartz LE 3-D-1S $1 \mathrm{~Hz}$ seismometer and a Nanometrics Orion data logger were deployed for the experiment. Figure 2 shows the location of the stations and the explosion point that triggered the rockfall. All data were recorded at a sampling rate of $200 \mathrm{~Hz}$. Pictures and video images were taken during the experiment. In addition, a subsequent Laser scanning survey of the affected area using an ILRIS 3-D Laser scanner was performed (Fig. 2). This information allowed us to generate the digital geometry of the slope and to obtain the coordinates of the detachment area, rockfall volume, height of free fall and rockfall trajectory following the method described in Abellán et al. (2006).

The explosives were placed in the slope, $180 \mathrm{~m}$ above our instruments (Fig. 2). As a result of the explosion, a rock of approximately $75 \mathrm{~m}^{3}$ broke into smaller fragments. Dozens of boulders ranging from $10^{-4} \mathrm{~m}^{3}$ to $5 \mathrm{~m}^{3}$ impacted onto the ground at different places. Most of the rocks fell down on a terrace just below the release zone (Fig. 2). The impact generated a mass flow composed of a mixture of rocks, sand and dust that ran down the slope about $60 \mathrm{~m}$ and impacted onto the road $10 \mathrm{~m}$ below (Fig. 8). Some boulders were not retained by the previously installed protection walls along the road and continued to roll downhill approximately $200 \mathrm{~m}$. After the rockfall event, a survey of the deposition area was carried out. The rockfall fragments were scattered over the road which also was covered with a thin layer of fine grain, dust and sand. The maximum block size was estimated from the deposits to be $5 \mathrm{~m}^{3}$. Most of the deposits were concentrated at the intersection between the rockfall trajectory and the road. However, some big boulders $\left(1 \mathrm{~m}^{3}\right)$ also landed near sensor B (Fig. 2).

\section{Data Analysis and Results}

In this work the seismic signals recorded at stations A and B during the rockfall experiment released on 14 February 2007 in the Montserrat massif (Fig. 2) are analyzed. Time series, time-frequency evolution, particle motion and polarization analysis of the seismic signals and seismic energy estimation were performed in order to provide quantitative evidence on the suitability of seismic methods for the detection, localization, and size determination of rockfall events.

Time series analysis was performed through correlations of the seismic signals with the video images taken of the event (Fig. 6). Our aim was to identify the different phases of the rockfall event in the time series. The $\mathrm{Z}, \mathrm{N}-\mathrm{S}, \mathrm{E}-\mathrm{W}$ components of the seismic signals recorded at stations $\mathrm{A}$ and B during the experiment are shown in Fig. 3. The seismic signals of the explosion are included. The time series analysis indicates that seismograms are complex with an irregular envelope showing several energetic pulses. The time duration of the signals exceeding the background noise is $30 \mathrm{~s}$. Horizontal components show higher amplitudes than 


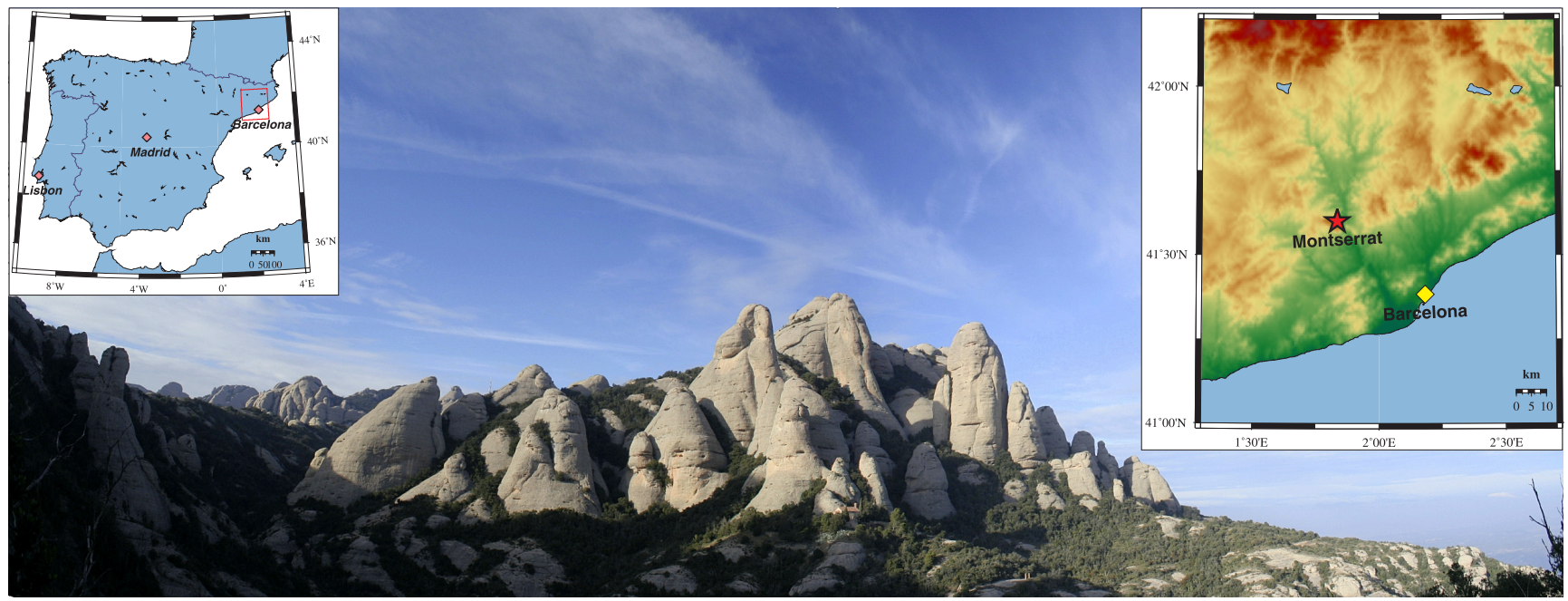

Fig. 1. General view of the Montserrat massif located $40 \mathrm{~km}$ North-West from Barcelona, Spain. Top left inset map of the Iberian Peninsula. Top Right inset detailed location map.

those of vertical components (Z), especially the components recorded at station $\mathrm{B}$. This was expected given the proximity of this station to the boulder impacts onto the ground and the mass flow. The main sources of the different wave packets observed in the time series (Fig. 3) were identified from the detailed comparison of the seismic signals with the video images obtained during the experiment. A more detailed plot of the vertical component seismograms from stations A and B with a common base of time is presented in Fig. 4: 1 Identifies the arrival of the $\mathrm{P}$ waves from the explosion; 2 corresponds to the arrival of the acoustic wave produced by the explosion; The seismic waves of the explosion accompanied by acoustic waves are separated in time from the rockfall signals; 3 coincides with the impacts onto a ledge of the wall of some blocks that initiated a free fall after the explosion. The ledge is placed $55 \mathrm{~m}$ below the explosion point (Fig. 2); 4 corresponds to the impact of the first boulder onto the terrace situated $120 \mathrm{~m}$ below the explosion point (Fig. 2). Immediately after 4 , the seismic signals amplitude increases until 5 . The time interval between 5 and 6 coincides with the mass flow triggered by the impact of the rockfall onto the terrace described above. The source of the high amplitude peaks observed between 6 and 7, identified with the help of the video images, corresponds to the impacts of four big blocks on the road. After 7 most of the mass movement ceased, although some small impacts caused by small boulders impacting on the road could still be recorded. In order to corroborate our observations we estimated the free fall time of some boulders from the seismic time series. The time interval between 1 and $3\left(t_{13}=3.42 \mathrm{~s}\right)$ corresponds to a free fall distance of $57 \mathrm{~m}$, while the time interval between 1 and $4\left(t_{14}=4.95 \mathrm{~s}\right)$ corresponds to a free fall distance of $120 \mathrm{~m}$. These values are in good agreement with those obtained from the geometrical

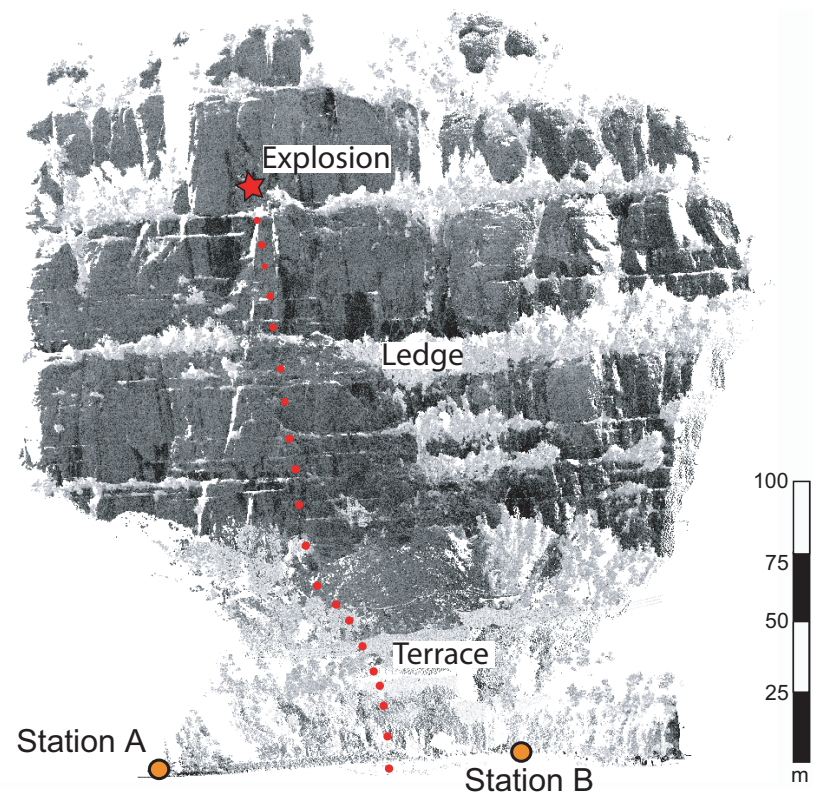

Fig. 2. Location of seismic stations $A$ and $B$ and explosion point on a laser scanner image. Rockfall trajectory (red dots) and impact areas are also indicated.

characteristics of the slope obtained from the laser scanning measurements: $55 \mathrm{~m}$ and $120 \mathrm{~m}$ for the distances from the explosion point to the ledge of the wall and to the terrace, respectively (Fig. 2). 

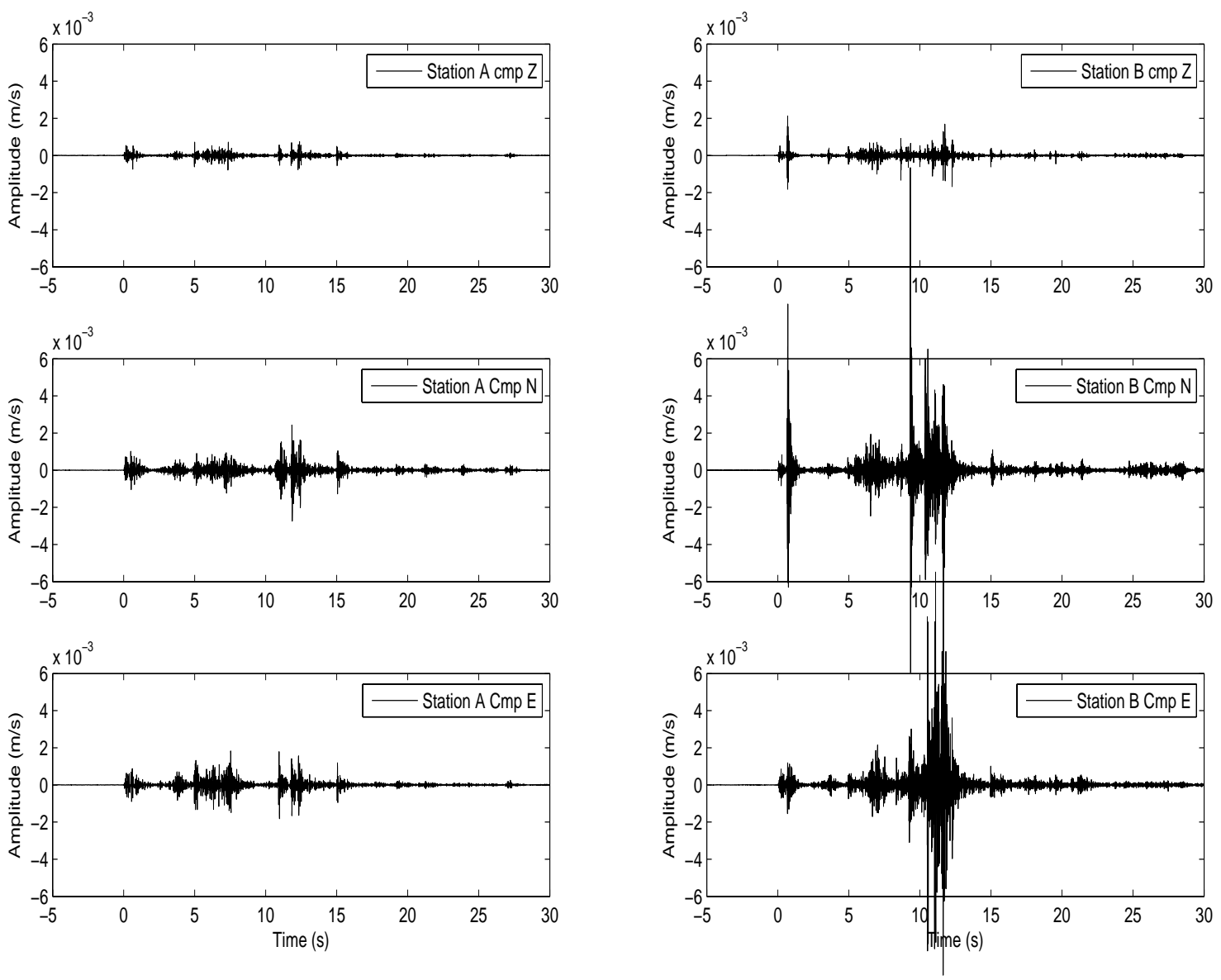

Fig. 3. From top to bottom Z, N-S, E-W components of the seismograms recorded during the artificially released rockfall on 14 February 2007. Left: station A. Right: station B.

The time-frequency evolution of the seismic signals was also investigated with the aim of identifying characteristic features useful for detection and signal recognition purposes. Any specific trend in this representation could be helpful in this regard. The time-frequency evolution (running spectra) analysis was based on the short time Fourier transform, which provides the frequency evolution in time of the seismic signals generated by the rockfall event. In Figure 5 the running spectra (RS) (time window $1.28 \mathrm{~s}, 50 \%$ of overlapping and Hanning window taper) of the vertical component of the seismic signals recorded at stations A and B are shown. The distinct parts are identified and numbered from 1 to 7 as in Figure 4. Both the explosion seismic signals and rock impacts on the ground present sharp energetic bands filling the complete frequency band. This representation confirms what was also observed in the seismograms i.e. the energy attenuation of rock impacts seems to be very strong, allowing us to recognize signals corresponding to consecutive rock impacts (Fig. 5). Unlike the explosion and rock impacts, the mass flow seismic signals (time interval between 5 and 6) present a gradual increase in the spectral amplitudes in time. This effect, which is better observed at one station (B), depends on the relative situation of the mass movement and recording station. This feature is commonly observed in other mass movements (Suriñach et al., 2005).

The procedure to locate the impact was based on the study of the polarization of the seismic signals. Polarization analysis yields three parameters that express the polarization behaviour observed in a particle motion representation: (1) linearity, (2) dip and (3) azimuth. For an isotropic medium, the particle motion of a compressional wave is oriented in the direction of the wave propagation. Consequently, the particle motion is parallel to the ray path. In contrast, shear waves show particle motion perpendicular to the direction of propagation. The particle motion lies within a plane perpendicular to the propagation direction and its orientation depends on the characteristics of the source (Tatham and McCormack, 1991). Particle motion plots obtained from three-component sensors enables us to determine the direction of arrival (azimuth) of the compressional waves. In this work, the analysis 


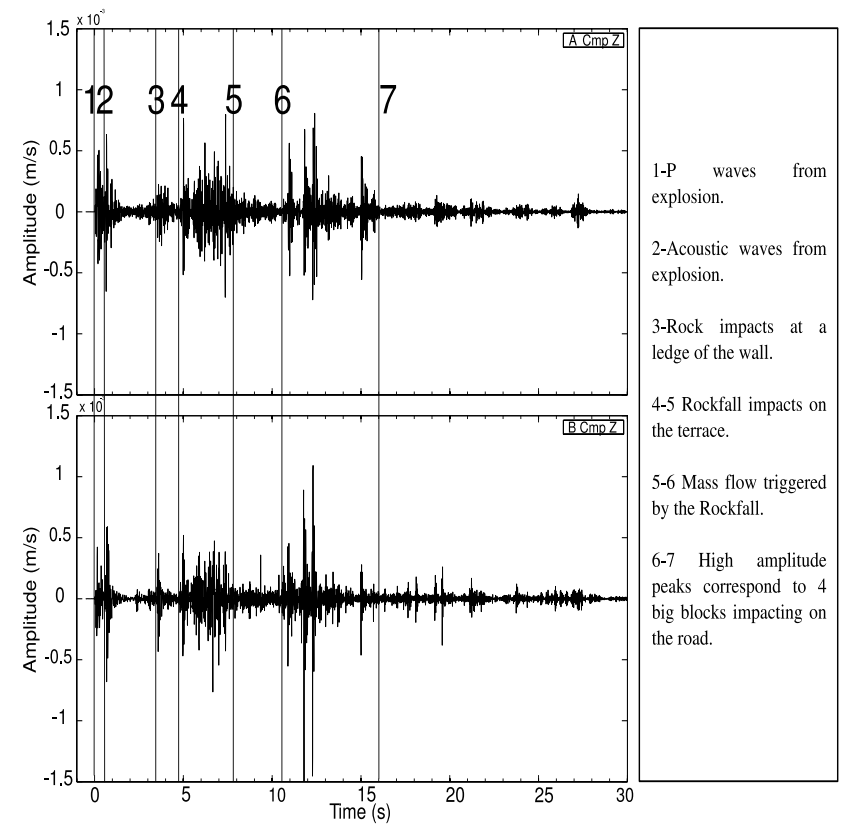

Fig. 4. Seismograms of the vertical component with identification of different wave packets after comparison with video images. Top: station A. Bottom: station B.

of the polarization behaviour over time intervals was adapted from Jurkevics (1988) and Vidale (1986). Taking N samples as corresponding to a time interval for each one of the three components $u_{i}, i=1,3(W-E, N-S, Z)$ of the ground motion (velocity) recorded at one station, the covariance matrix is obtained as

$C_{i j}=\frac{1}{N} \sum_{s=1}^{N} u_{i}(s) u_{j}(s)$

The covariance matrix $\mathbf{C}(3 \times 3)$ is real and symmetric and represents the polarization ellipsoid that best fits the data. The principal axes of this ellipsoid can be obtained by solving (Eq. 2)

$(\mathbf{C}-\mathbf{\Lambda} \mathbf{I}) \mathbf{P}=0$

where $\mathbf{I}$ is the identity matrix, and $\mathbf{P}\left(\boldsymbol{p}_{1}, \boldsymbol{p}_{2}, \boldsymbol{p}_{3}\right)$ and $\boldsymbol{\Lambda}$ $\left(\lambda_{1}, \lambda_{2}, \lambda_{3}\right)$ the eigenvectors and eigenvalues, respectively. At each recording station, the eigenvector $\boldsymbol{p}_{1}(W-E, N-S, Z)$ associated with the maximum eigenvalue $\left(\lambda_{1}\right)$ of the data covariance matrix yields the dominant polarization direction $\theta$ (Eq. 3) and the type of polarization or linearity (Eq. 4).

$\theta=\arctan \left(\frac{p_{1}(N-S)}{p_{1}(W-E)}\right)$

$L=1-\left(\frac{\lambda_{2}-\lambda_{3}}{2 \lambda_{1}}\right)$

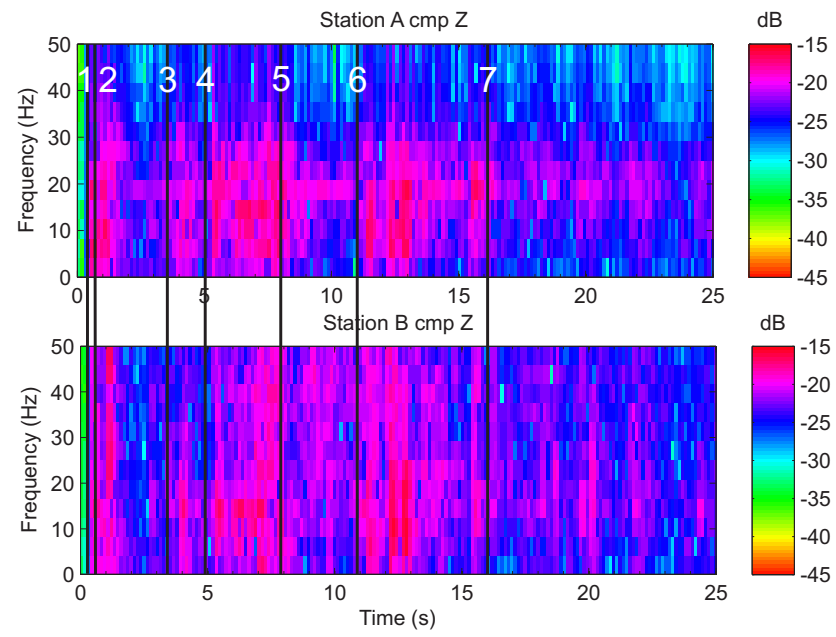

Fig. 5. Running spectra of the $\mathrm{Z}$ component seismogram. Same identification as in Fig. 4. Top: station A. Bottom: station B.

Equation 4 gives us $L$, with values between 0 and 1 , which is a measure of the degree of linearity of the polarization of the wavefield. For a perfectly linearly polarized wave, this value is 1 and is smaller for elliptically polarized waves.

The azimuths of the incident waves generated by the explosion and the rock impacts using the particle motion plots were determined. The time series were filtered with a $20 \mathrm{~Hz}$ low pass fourth order Butterworth filter in order to eliminate high frequency wave contributions due to scattering and to the small heterogeneities of the ground. Windows of $25 \mathrm{sam}-$ ples were selected to perform the polarization analysis after a trial and error process of trade off between window length and linearity. Wave packets with high linearity ( $L$ approx 1$)$ were chosen for azimuth determination.

Figure 7a shows the particle motion plot for the horizontal components of the first wave packet from the explosion (Fig. 4 number 1) recorded at stations A and B. Each particle motion plot is centred at the station and the line indicates the selected azimuthal direction. As expected, the line points toward the explosion point. Linearity obtained at station A $\left(L_{\mathrm{A}}=0.78\right)$ is smaller than that obtained at $\mathrm{B}\left(L_{\mathrm{B}}=0.90\right)$, which yields a better azimuth estimate. Figure $7 \mathrm{~b}$ shows in the same representation as in Fig. 7a the particle motion plots of the $0.125 \mathrm{~s}$ wave packets recorded at the two stations at instant $t=11.82 \mathrm{~s}$, which corresponds to the impact of a big boulder onto the road near station $\mathrm{B}$, which could be clearly identified by the video images and the deposits survey (Fig. 6). Both particle motion representations show a high degree of linearity and the polarization directions point correctly to the road near B where a big boulder impacted at that time (from video images).

Figure 8 shows the particle motion of the first impact of the rockfall onto the terrace ( $t=4.95 \mathrm{~s}$ Fig. $6 \mathrm{f})$. Details of the wave packets of the three components for stations A and B 


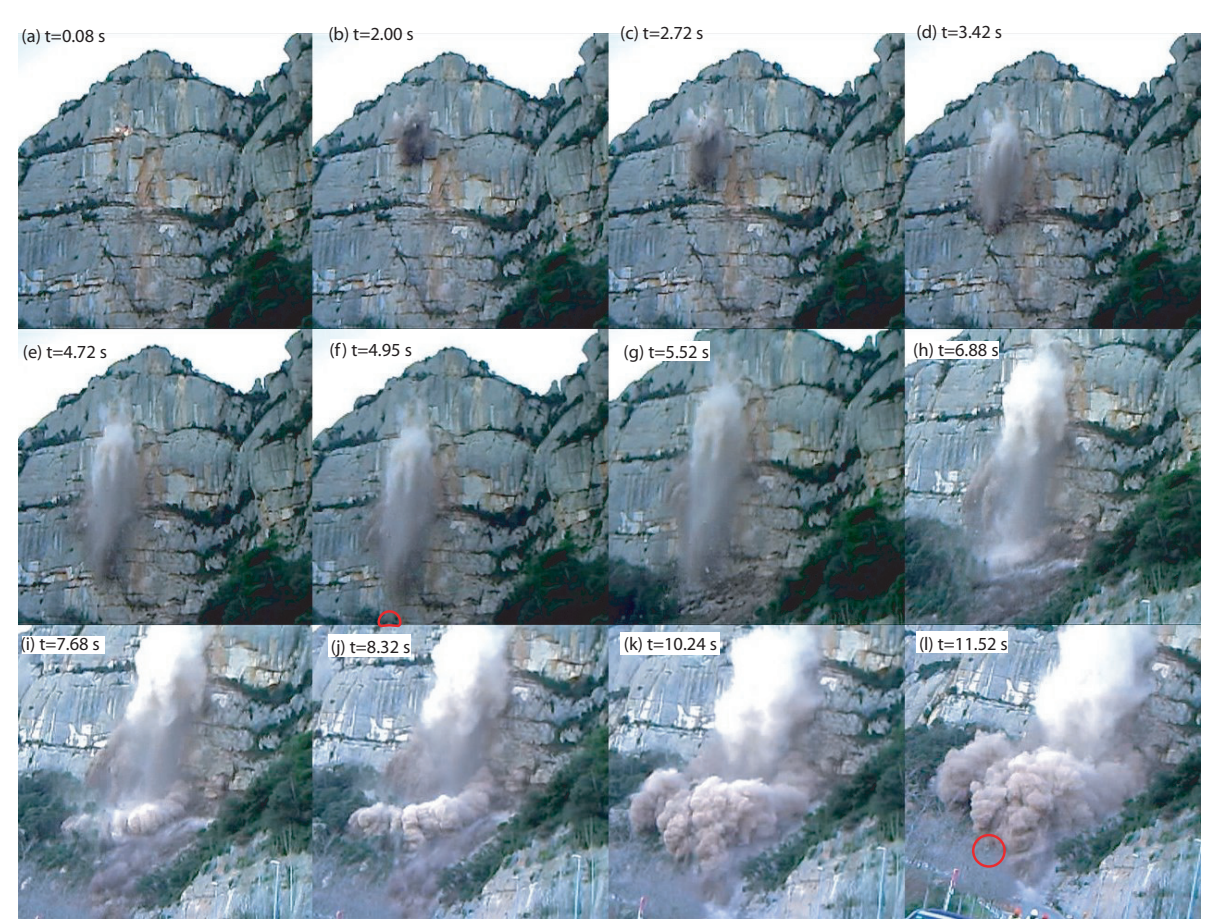

Fig. 6. Significant images from the video of the artificially released rockfall. Red circles indicate impact on terrace $(t=4.95 \mathrm{~s})$ and boulder mentioned in the text $(t=11.52 \mathrm{~s})$.
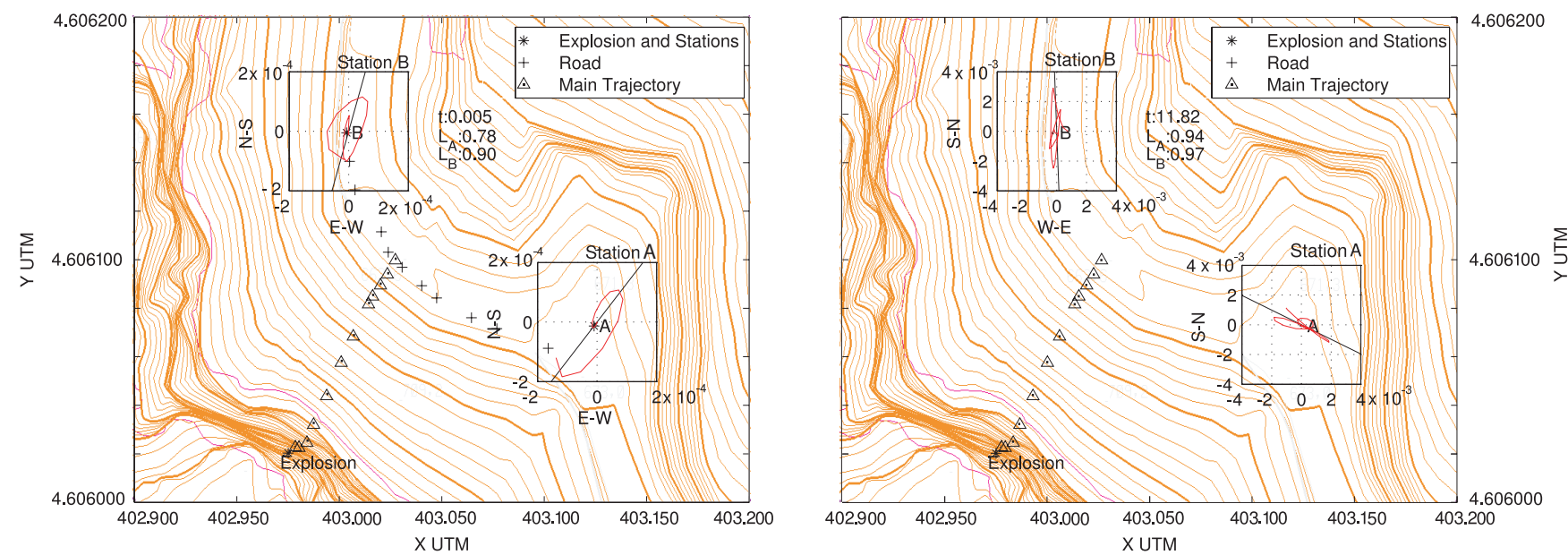

Fig. 7. Explosion (left: a) and rockfall impact (right: b) site determination using particle motion analysis. Location of stations A and B, road and rockfall trajectory are indicated. Direction of polarization from particle motion analysis for stations A and B on local axes. Time origin $(t)$ of the analysed wave packet and Linearity $\left(L_{\mathrm{A}}, L_{\mathrm{B}}\right)$ are also presented. Levelling curves from 1:5000 topographic map (ICC).

used are shown in the figure. The particle motion plot $\left(L_{\mathrm{A}}=\right.$ 0.80 ) at station A points correctly towards the base of the wall. At $\mathrm{B}$, although the linearity is smaller $\left(L_{\mathrm{B}}=0.60\right)$, the particle motion plot also points to the wall. The direction indicated is less precise than at A (obtained from video images) but a correct estimate of the direction of the incoming waves is possible.
The seismic energy recorded during a rockfall event may be a measure of its size. A first order approximation of the energy dissipated in form of seismic waves by the rock impacts onto the ground can be obtained following Eq. 5,

$$
E_{s}=\int_{t_{1}}^{t_{2}} 4 \pi r^{2} \rho c u_{\mathrm{env}}(t)^{2} e^{\alpha r} d t
$$



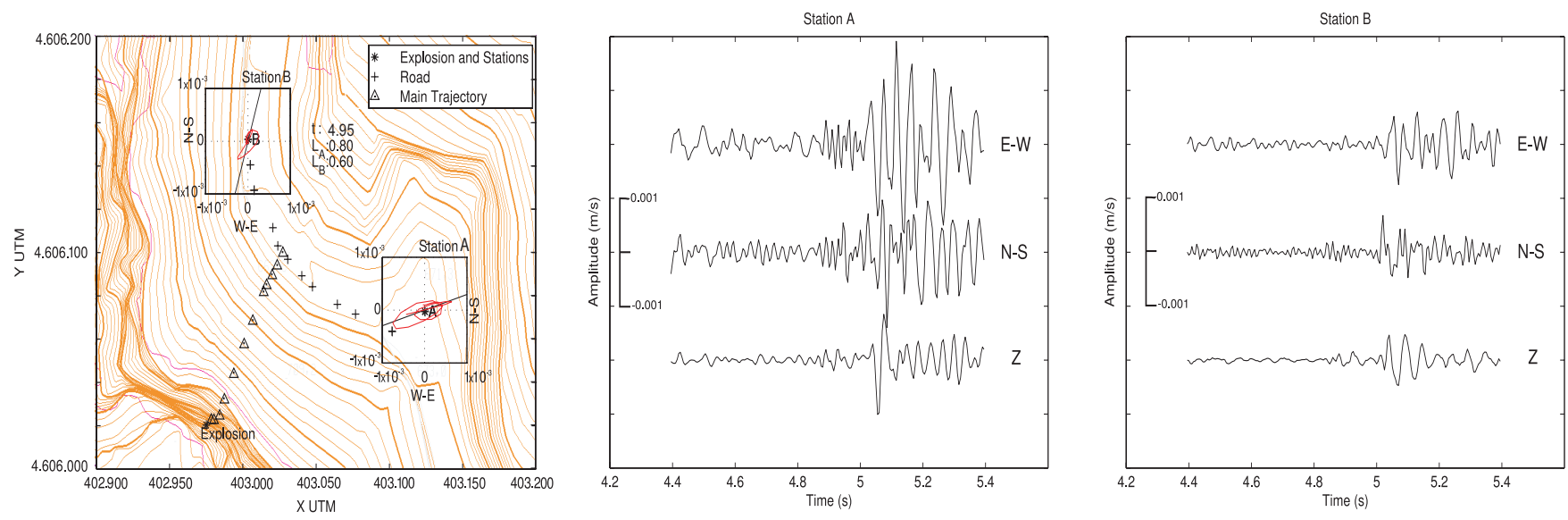

Fig. 8. Rockfall impact site determination using particle motion analysis. Same representation as in Fig. 7. Details of the 3 component wave packets at stations $\mathrm{A}$ and $\mathrm{B}$ used for determination.

$u_{\mathrm{env}}(t)=\sqrt{u(t)^{2}+h t(u(t))^{2}}$

where $r$ is the distance sensor-event, $\rho$ is the ground density, $c$ is the phase velocity of the seismic waves, $u_{\text {env }}(t)$ is the amplitude envelope of the recorded signal (ground velocity) obtained through the Hilbert transformation $(h t)$ as presented in Eq. (6) and $\alpha$ is the damping factor that accounts for anelastic attenuation of waves and usually depends on the signal frequency. Here, the frequency dependence of the attenuation is neglected. The energy dissipated by means of seismic waves was calculated for the wave packets between 4 and 5 recorded at stations A and B (Fig. 4) corresponding to the impacts of the main part of the rockfall onto the terrace $120 \mathrm{~m}$ below the explosion point (Fig. 2). Equation 6 was applied to the three components of the ground motion (velocity) to obtain the total amplitude envelope for inclusion in Eq. 5. Prior to this calculation, velocity $c$ and attenuation factor $\alpha$ of the seismic waves at the site were determined. The use of the explosion records obtained at stations A and $\mathrm{B}$ to achieve these values was not feasible given the similarity of the distances between the explosion points to the two stations. We therefore selected for this evaluation the wave packet corresponding to the impact of the first block onto the terrace $120 \mathrm{~m}$ below the explosion (Fig. 8). The distances from stations A and B to the impact point obtained from the analysis of the laser scanner data were 126 and $103 \mathrm{~m}$, respectively. An estimation of $c$, velocity of primary waves, was obtained by standard picking procedures and resulted in $920 \mathrm{~ms}^{-1}$. The superficial ground density was selected to be $1900 \mathrm{~kg} \mathrm{~m}^{-3}$ in good agreement with the $\mathrm{P}$ wave velocity obtained (Xia et al., 2002).

The attenuation factor $\alpha$ was estimated using the methodology proposed by Zywicki and Rix (1999). The procedure yields a frequency dependent value of $\alpha$ for each of the 3 ground motion components. The $\alpha$ value obtained for the range from $5 \mathrm{~Hz}$ to $25 \mathrm{~Hz}$ was taken as $0.0370 \mathrm{~m}^{-1}$. The calculated values of the seismic energy dissipated for the interval between 4 and 5 are $46.5 \mathrm{MJ}$ and $34.9 \mathrm{MJ}$ for stations $\mathrm{A}$ and $\mathrm{B}$, respectively on the assumption that the values of $c$ and $\alpha$ are correct. Despite being of the same order, the discrepancy between these values may be ascribed to directivity and/or site effects and to the fact that the approach adopted in this paper does not account for the frequency dependence of the attenuation factor. As expected the values obtained are smaller than the initial potential energy dissipated by the rockfall impact onto the ground because of the existence of other energy dissipation processes (rock fracture, heat, etc.). For a height of $120 \mathrm{~m}$ of free fall and assuming that $90 \%$ of the total mass $(M=187 T)$ impacted onto the ground in the selected time interval the potential energy estimated $(E p=\mathrm{mgh}$ ) was $E p=200 \mathrm{MJ}$, approximately 4 times greater than that obtained. This difference, in addition to other mechanisms of energy dissipation, could be due to energy absorption given the type of soil in the terrace (mainly composed of sediments) where the rocks impacted. Moreover, we cannot disregard the strong dependency of $\alpha$ in the evaluation of the energy.

\section{Conclusions}

Our findings corroborate the feasibility and validity of seismic methods for the detection of rockfall events, their localization and size determination. To this end, we analyzed the seismic data obtained at two 3 component seismic stations installed specifically to monitor the artificially triggered rockfall of approximately $75 \mathrm{~m}^{3}$ at the Montserrat massif. This value was derived from laser scanner data analysis. The source of the different wave packets in the time series was identified by comparing the seismograms and video images simultaneously obtained. The results indicate that each impact of the rockfall onto the ground produces strong, mainly 
linearly polarized P-waves. Polarisation analysis of P-wave packages from 3 component seismic records was used to successfully locate the explosion and two rock impacts of larger blocks that impacted onto the ground. The success of this technique demands a high linearity of the waves to correctly determine the azimuth. It should be pointed out, however, that at least two seismic signals simultaneously recorded at two sites arranged in an appropriate geometry with respect to the moving source are necessary. The time-frequency evolution of the recorded time series to identify characteristic features useful for detection purposes was analysed. Seismic signals from the explosion and rock impacts onto the ground show energetic bands that fill the whole frequency range of the spectra, appear suddenly, and attenuate rapidly. In contrast, seismic signals generated by the slide rocks present a gradual increase in the spectral amplitudes in time. This time-frequency evolution is different from that of other seismogenic sources (e.g. earthquakes, explosions or a single rock impacts) and resembles the frequency evolution observed in the seismic records from other mass movements (Suriñach et al., 2005). Should this observation be corroborated in future studies, the method presented would be a useful tool for seismic detection of rocks that move downhill.

The seismic energy dissipated by the rockfall impact onto the terrace was estimate using recordings from two stations. The values obtained were $46.5 \mathrm{MJ}$ and 34.9 MJ. The discrepancy between values may be ascribed to directivity and/or site effects. The procedure for energy determination strongly depends on the velocity of seismic waves and the attenuation factor of the site. In our case the values obtained using two stations and one event were $920 \mathrm{~ms}^{-1}$ and $0.0370 \mathrm{~m}^{-1}$. A more detailed seismic characterization of the site (with more stations and events) would provide a more accurate seismic energy determination. However, the methodology presented can be used to obtain estimates of the seismic energy released by a rockfall. The values obtained for the dissipated seismic energy are 4 times smaller than the kinetic energy of the impacted mass (200 MJ). Smaller value for the seismic energy were expected for the following reasons: a) the mass did not completely stop on impact (rebound partially elastic), b) the presence of other energy dissipating processes such as rock fragmentation and heat, and c) in this particular case the rock impacted onto a cushion of soft material that absorbed part of the seismic energy. Other results for energy calculation of rockfall impacts involving greater source-receiver distances (Deparis, 2007) show energy dissipated ratio values of the order of $10^{-3}$, which is in agreement with the behaviour of seismic waves. It may be concluded that detection, localization and size determination of a rockfall event based on the correct deployment of two 3 component seismic stations and on a detailed analysis of the recorded seismograms are feasible. Consequently, the methodology presented is useful in detecting and characterizing rockfall events for rockfall cataloguing and subsequent land use planning.
Acknowledgements. The authors would like to thank to M. Janeres and the GeoCat Company for facilitating the installation of the instruments. This study was funded by the Spanish MEC projects CGL2006-06596, CGL2005-02250 and CSD2006-00041. We are indebted to K. G. Hinzen and H. Balder Havenith for their helpful and constructive revision of the manuscript.

Edited by: T. Glade

Reviewed by: H.-B. Havenith and K. Hinzen

\section{References}

Abellán, A., Vilaplana, J. M., and Martínez, J.: Application of a long-range Terrestrial Laser Scanner to a detailed rockfall study at Vall de Núria (Eastern Pyrenees, Spain), Eng. Geol, 88(3-4), 136-148, 2006.

Deparis, J.:Étude des éboulements rocheux par méthodes géophysiques, Ph. D., Université Joseph Fourier, Grenoble, p. 247, 2007.

Jurkevics, A.: Polarization analysis of three-component array data, Bull. Seismol. Soc. Am., 785, 1725-1743. 1988.

Norris, R. D.: Seismicity of rockfalls and avalanches at three Cascade Range volcanoes; implications for seismic detection of hazardous mass movements, Bull. Seismol. Soc. Am., 84, 19251939, 1994.

Richart, F. E., Wood, R. D., and Hall, J. R.: Vibration of soils and foundations, Prentice-Hall, New Jersey, USA, p. 414, 1970.

Sabot, F., Naaim, M., Granada, F., Surinach, E., Planet, P., and Furdada, G.: Study of the Avalanche Dynamics by means of Seismic Methods, Image Processing Techniques and Numerical Models, Ann. Glaciol., 26, 319-323, 1998.

Suriñach, E.: Spanish avalanche research: experimental sites and seismic measurements Recherches espagnoles dans le domaine des avalanches: sites expérimentaux et mesures sismiques, International Seminar on Snow and Avalanches Test Sites, 173-183, Grenoble 2004.

Suriñach, E., Vilajosana, I., Khazaradze, G., Biescas, B., Furdada, G., and Vilaplana, J. M.: Seismic detection and characterization of landslides and other mass movements, Nat. Haz. Earth Sci., 5, 791-798, 2005.

Tatham, R. H. and McCormack, M. D.: Multicomponent seismology in petroleum exploration, Society of Exploration Geophysicists, p. 248, 1991.

Vidale, J. E.: Complex polarization analysis of particle motion, Bull. Seismol. Soc. Am., 76(5), 1393-1405, 1986.

Vilajosana I., Bacher, M., Suriñach, M., Hübl H., Khazaradze, G., and Garcia de Yebenes L.: Mud flow detection experiments at Schesatobel, Austria, Geophysical Research Abstracts, Vol. 9, 07765, 2007 SRef-ID: 1607-7962/gra/EGU2007-A-07765, 2007.

Xia J., Miller, R. D., Park, C. B., and Tian, G.: Determining Q of near-surface materials from Rayleigh waves, J. Appl. Geophys., 51(2), 121-129, 2002.

Zywicki, D. J. and Rix, G. J.: Frequency-Wavenumber Analysis of Passive Surface Waves, The Symposium on the Application of Geophysics to Engineering and Environmental Problems, Conference Proceedings, 14-18 March 1999, Oakland, California, USA, 75-84, 1999. 